\title{
TỶ LỆ HẠ ĐƯờnG HUYẾT TỬ GHI NHẬN VÀ CÁC YẾU TỐ LIÊN QUAN Ở NGƯỜI BỆH ĐÁI THÁO ĐƯờNG TÍP 2 TẠI VIẸTT NAM
}

Võ Tuấn Khoa', Chu Thị Thanh Phương', Lê Duy Hung ${ }^{1}$, Nguyễn Thy Khuê ${ }^{2}$, Aya Goto ${ }^{3}$, Chihaya Koriyama ${ }^{4}$ và Hirohide Yokokawa ${ }^{5}$

1. Bệnh viện Nhân Dân 115, TPHCM; 2. Hội Y học TPHCM

3. Đại học Y khoa Fukushima, Nhạt Bản 4. Đại học Kagoshima, Nhật Bản

DOI: $10.47122 / v j d e .2020 .41 .8$

5. Đại học Juntendo, Nhật Bản

\section{ABSTRACT \\ Frequency and predictors of self reported hypoglycemia among type 2 diabetes outpatients in Vietnam}

Background: Hypoglycemia is one of the most serious complications among type 2 diabetes patients, but have been addressed less in clinical practice. Purpose: Our study aims are to determine frequency and predictors of unconfirmed and self reported hypoglycemia in type 2 diabetes outpatients. Methods: A cross sectional survey with 669 subjects was conducted at People's Hospital 115, HCM city in 2017. This program was announced through leaflets and hospital postings. We included type 2 diabetes patients, 18 years or older and diabetes duration of at least 1 year.Hypoglycemia was defined as an experience of at least four typical symptoms such as hunger, sweating, tremor, headache, dizziness, blurred vision and confusion over the past 6 months. Identification of hypoglycemia did not include self blood glucose findings. Results: The prevalence of self reported hypoglycemia was $58 \%$ of diabetic outpatients and was associated with insulin use [adjusted odds ratio $(\mathrm{aOR}=6.46), 95 \%$ confidence interval $(95 \%$ CI 3,$88 ; 10,7)]$, history of hypoglycemia hospitalization over the past 12 months (aOR=5,54, 95\% CI 1,79;17,2), sulfonylureas use $\quad(\mathrm{aOR}=1,93, \quad 95 \% \quad \mathrm{CI} \quad 1,17 ; 3,17)$. Discussion: Self reported hypoglycemia is frequent among Vietnamese diabetic patients. Past admission of hypoglycemia and use of agents (insulin, sulfonylureas) are significant predictors of hypoglycemia. Conclusion: Prevalent self reported hypoglycemia in
Vietnamese type 2 diabetes patients could be prevented by increasing awareness for patients and physicians with regard to more careful treatment for those with history of hypoglycemia hospitalization and under insulin secretagogues.

Key word: diabetes, hypoglycemia, selfreported

\section{TÓM TẮT}

Đặt vấn đề: Hạ đường huyết là một trong các biến chứng nghiêm trọng của đái tháo đường típ 2 nhưng lại ít được quan tâm đến trong thực hành lâm sàng. Mục tiêu nghiên cứu: Nghiên cứu của chúng tôi nhằm xác định tỷ lệ hạ đường huyết tự ghi nhận và không kèm thử đường huyết trong cơn cùng với các yếu tố liên quan ở người bệnh đái tháo đường típ 2 ngoại trú. Phương pháp nghiên cúu: Nghiên cứu cắt ngang với cỡ mẫu 669 người được tiến hành tại bệnh viện Nhân Dân 115, TP. Hồ Chí Minh năm 2017. Chương trình được công bố trên các tờ rơi và các poster trong bệnh viện. Tiêu chuẩn chọn vào là đái tháo đường típ 2 , từ 18 tuổi trở lên và thời gian mắc đái tháo đường tối thiểu 1 năm. Hạ đường huyết được định nghĩa là người bệnh có ít nhất 4 trong 7 triệu chứng sau đói bụng, đổ mồ hôi, run rẩy, nhức đầu, chóng mặt, nhìn mờ và lú lẫn xảy ra trong vòng 6 tháng trước đó. Việc xác định hạ đường huyết không bao gồm việc tự thử đường huyết bằng máy thử cá nhân. Kết quả: Tỷ lệ hạ đường huyết tự ghi nhận là $58 \%$ trong số người bệnh đái tháo đường ngoại trú và có mối liên quan có ý nghĩa thống kê với dùng insulin [OR hiệu chỉnh=6,46), 95\% KTC 3,$88 ; 10,7)$ ], tiền sử nhập viện vì hạ 
đường huyết trong vòng 12 tháng qua ( $\mathrm{OR}$ hiệu chỉnh=5,54, 95\% KTC 1,79;17,2), dùng sulfonylureas (OR hiệu chỉnh=1,93, 95\% KTC 1,17;3,17). Bàn luận: Hạ đường huyết tự ghi nhận rất hay gặp ở người bệnh đái tháo đường Việt Nam. Tiền sử nhập viện vì hạ đường huyết và việc dùng các thuốc (insulin, sulfonylureas) là các yếu tố tiên lượng hạ đường huyết. Kết luận: Tỷ lệ phổ biến của hạ đường huyết tự ghi nhận ở người bệnh đái tháo đường típ 2 có thể được ngăn ngừa bằng việc gia tăng nhận thức của thày thuốc lẫn người bệnh về việc thận trọng điều trị cho những người có tiền sử hạ đường huyết trước đó và dùng nhóm thuốc kích thích tiết insulin.

Tù khóa: đái tháo đường, hạ đường huyết, tụ ghi nhận

Chịu trách nhiệm chính:Võ Tuấn Khoa

Ngày nhận bài: 10/8/2020

Ngày phản biện khoa học: 11/9/2020

Ngày duyệt bài: $12 / 10 / 2020$

Email: tkhoa.vo@gmail.com

Điện thoại: 0937763774

\section{1. ĐĂT VẤN ĐỀ}

Hạ đường huyết là một tình huống cấp tính xảy ra khi đường huyết giảm dưới một ngưỡng nhất định. Ở người bệnh đái tháo đường, hạ đường huyết có tác động đáng kể lên chất lượng cuộc sống, công việc làm, mối tương tác xã hội và khả năng lái xe [11], [13], [15]. Ngoài các tác động trực tiếp, hạ đường huyết còn gây ra các tác động gián tiếp quan trọng trên hệ quả sức khỏe dài hạn từtuân thủ điều trị kém đến tình trạng tăng đường huyết cố ý do lo sợ và tránh cơn hạ đường huyết [14].

Cho đến nay, tỷ lệ hạ đường huyết được báo cáo trong các thử nghiệm lâm sàng và nghiên cứu quan sát hầu hết dựa vào kết quả đo đường huyết [1], [16], và/hoặc ghi chép cơn hạ đường huyêt trong hồ sơ bệnh án [6], [7]. Trong thực tế lâm sàng, không phải tất cả người bệnh đái tháo đường có thể tự thử đường huyết thường xuyên và trao đổi với bác sĩ về các triệu chứng nghi ngờ hạ đường huyết của mình mà không có thử đường huyết làm bằng chứng. Do vậy, việc tự ghi nhận hạ đường huyết có thể phản ánh đầy đủ hơn những cơn hạ đường huyết của người bệnh trong đời sống hàng ngày và có thể cung cấp nhiều thông tin cho bác sĩ điều trị.

Nghiên cứu được chúng tôi tiến hành nhằm hai mục tiêu: (1) Xác định tỷ lệ ha đường huyết tư ghi nhận và (2) Các yếu tố liên quan với hạ đường huyết ở ngườ bệnh đái tháo đường típ 2.

\section{2. ĐỐI TƯợNG VÀ PHƯƠNG PHÁP NGHIÊN CÚU}

Đây là nghiên cứu cắt ngang mô tả và phân tích các đối tượng tham gia chương trình giáo dục sức khỏe tại Khoa Nội tiết, Bệnh viện Nhân Dân 115 trong năm 2017 thỏa tiêu chí: đái tháo đường típ 2 , tuổi từ 18 trở lên, thời gian mắc bệnh tối thiểu 12 tháng (tính đến thời điểm vào nghiên cứu). Tiêu chuẩn loại trừ bao gồm ít nhất một tiêu chí như (1) mắc bệnh nội khoa nặng; (2) suy giảm nhận thức trầm trọng.

Để xác định tình trạng hạ đường huyết, các đối tượng tham gia được yêu cầu đọc một bảng liệt kê bao gồm 7 triệu chứng như đói bụng, vã mồ hôi, run tay chân, chóng mặt, nhức đầu, nhìn mờ, kém tập trung và ghi nhận sự hiện diện các triệu chứng trong vòng 6 tháng qua. Hạ đường huyết được xác định khi người bệnh ghi nhận có ít nhất $4 / 7$ triệu chứng trên [3].

Dữ liệu thu thập được nhập bằng phần mềm Excel 2010 và được tóm lược dưới dạng tỷ lệ đối với biến định tính và trung bình (độ lệch chuẩn) với biến liên tục. Mối liên hệ giữa tình trạng hạ đường huyết và các yếu tố liên quan bằng chỉ số odds ratio $(\mathrm{OR})$. Để khử đồng thời các yếu tố gây nhiễu, mô hình hồi qui logistic đa biến được áp dụng để xác định mức đóng góp tương đối của các yếu tố đối với tình trạng hạ đường huyết. Khác biệt được xem có ý nghĩa thống kê khi giá trị p nhỏ hơn 0,05. Dùng phần mềm Stata phiên bản 12.0 để thực hiện các phép kiểm thống kê.

\section{KẾT QUẢ NGHIÊN CỨU}

Tổng cộng có 701 người được mời tham gia, trong đó có 21 trường hợp từ chối và 11 
ca không hoàn tất nghiên cứu, do vậy chúng tôi đưa vào phân tích 669 đối tượng tham gia (chiếm tỷ lệ 95,4\%).

Trong nghiên cứu này, tỷ lệ nữ/nam là $2 / 1$ với độ tuổi trung bình 63 năm. Phần lớn (81\%) là người đã về hưu với hơn $60 \%$ có trình độ trung học trở lên. Về các yếu tố liên quan lối sống, tỷ lệ hút thuốc lá, uống rượu bia và ít vận động lần lượt là $8,4 \% ; 17,4 \%$ và
$35 \%$. Thời gian trung vị bị đái tháo đường là 7 năm với $42 \%$ có sử dụng insulin và $4 \%$ có tiền sử nhập viện vì hạ đường huyết trong vòng 1 năm qua.

Dựa vào bộ câu hỏi tự đánh giá, cảm giác đói bụng thường gặp nhất $(60 \%)$ trong khi đó triệu chứng kém tập trung ít gặp nhất (11\%). Tỷ lệ hạ đường huyết tự ghi nhận trong nghiên cứu chúng tôi là $57,7 \%$.

Bảng 3.1. Các triệu chứng hạ đường huyết ( $\mathrm{n}=669)$

\begin{tabular}{|c|c|}
\hline Hạ ĐH tự ghi nhận & Tần suất (\%) \\
\hline Các triệu chứng & \\
\hline Đói bụng & $407(59,9)$ \\
\hline Vã mồ hôi & $384(56,6)$ \\
\hline Run tay chân & $361(53,2)$ \\
\hline Chóng mặt & $363(53,5)$ \\
\hline Nhức đầu & $247(36,4)$ \\
\hline Nhìn mờ & $166(24,4)$ \\
\hline Kém tập trung & $74(10,9)$ \\
\hline Tỷ lệ hạ ĐH tự ghi nhận & $392(57,7)$ \\
\hline
\end{tabular}

Kết quả phân tích hồi qui logistic đơn biến cho thấy các yếu tố như tuổi, phái tính, tiền sử bệnh mạch vành, tiền sử đột quị, tiền sử loét chân và tiền sử loét chân/đoạn chi không có liên hệ với tình trạng hạ đường huyết. Tuy nhiên, tỷ lệ hạ đường huyết tăng dần theo tuổi bệnh và mức HbAlc. Bên cạnh đó, việc sử dụng insulin, tiền sử nhập viện vì hạ đường huyết trong năm qua và tiền sử bệnh võng mạc làm tăng nguy cơ hạ đường huyết ngoại trừ việc dùng sulfonylureas làm giảm nguy cơ hạ đường huyết.

Áp dụng mô hình phân tích hồi qui logistic đa biến, các yếu tố dùng sulfonyluras (OR hiệu chỉnh $=1,93 ; 95 \%$ KTC 1,17-3,17; $\mathrm{p}=0,010)$; dùng insulin (OR hiệu chỉnh=6,46; 95\%KTC 3,88$10,7 ; \mathrm{p}=0,000)$ và tiền sử nhập viện vì hạ $\mathrm{OH}$ trong năm qua (OR hiệu chỉnh $=5,54 ; 95 \% \mathrm{KTC}$ $1,79-17,2 ; \mathrm{p}=0,003)$ là các yếu tố độc lập kết hợp với hạ đường huyết tự ghi nhận.

Bảng 3.2. Phân tích hồi qui logistic đơn biến

\begin{tabular}{|l|c|c|}
\hline \multicolumn{1}{|c|}{ Yếu tố } & OR thô $(\mathbf{9 5 \%}$ KTC) & p \\
\hline Tuồi (năm) & $0.99(0,98-1.01)$ & 0,245 \\
\hline Phái (nam/nữ) & $0,79(0,58-1.08)$ & 0,146 \\
\hline Thời gian ĐTĐ (năm) & $1,05(1,02-1,08)$ & 0,000 \\
\hline HbA1c (\%) & $1,15(1,06-1,25)$ & 0,001 \\
\hline Dùng sulfonylurea & $0,52(0.38-0,71)$ & 0,000 \\
\hline Dùng insulin & $3,97(2,82-5,59)$ & 0,000 \\
\hline TS nhập viện hạ ĐH & $4,28(1,46-12.5)$ & 0,008 \\
\hline TS bệnh mạch vành & $0,91(0,54-1,55)$ & 0,741 \\
\hline TS đột quị & $1,78(0,77-4,12)$ & 0,180 \\
\hline TS bệnh võng mạc & $4,29(1,25-14,8)$ & 0,021 \\
\hline TS loét chân/đoạn chi & $1,85(0,97-3,52)$ & 0,060 \\
\hline TS bệnh thận mạn & $1,48(0,85-2,56)$ & 0,162 \\
\hline
\end{tabular}

ĐTĐ: đái tháo đường; TS: tiền sử; $\mathrm{DH}$ : đường huyết; $\mathrm{OR}$ : odds ratio 


\section{BÀN LUẬN}

Nghiên cứu chúng tôi là một phần trong chương trình giáo dục đái tháo đường thực hiện tại khoa Nội tiết, Bệnh viện Nhân Dân 115. Tất cả người bệnh tham gia là những người bệnh điều trị ngoại trú. Trong nghiên cứu này, người bệnh trải qua các triệu chứng hạ đường huyết chủ yếu là đói bụng, vã mồ hôi, run tay chân và chóng mặt với tỷ lệ 50 đến $60 \%$. Đây cũng là các triệu chứng báo động của hệ thần kinh giao cảm khi mức đường huyết bắt đầu giảm. Kết quả này cũng tương tự trong nghiên cứu của Samya và cộng sự cho thấy tỷ lệ các triệu chứng hạ đường huyết thường gặp là chóng mặt $(72,3 \%)$; đổ mồ hôi $(44,2 \%)$; yếu cơ $(42,9 \%)$ và đói bụng $(42,4 \%)$ [9]. Trong khi đó, Shriraam V và cộng sự báo cáo triệu chứng yếu cơ và chóng mặt thường gặp nhất ở người đái tháo đường bị hạ đường huyết với tỷ lệ lần lượt là $76,2 \%$ và $74 \%[10]$.

Một kết quả quan trọng trong nghiên cứu của chúng tôi là hạ đường huyết tự ghi nhận (được định nghĩa có $\geq 4 / 7$ triệu chứng nghi ngờ hạ đường huyết mà không kèm theo thử đường huyết mao mạch) chiếm tỷ lệ $57,7 \%$. Đây là tỷ lệ cao có thể cho thấy tầm mức quan trọng của vấn đề sức khỏe trong điều trị đái tháo đường. Kết quả của chúng tôi thấp hơn trong một nghiên cứu tại Ethiopia[12] là $70,8 \%$ có thể do quần thể nghiên cứu bao gồm cả đái tháo đường típ 1 (chiếm 54\%) với hầu hết dùng insulin và cao hơn tại Ấn Độ[9] với tỷ lệ hạ đường huyết tự ghi nhận là $57,4 \%$, trong đó tiêu chí xác định hạ đường huyết dựa vào ít nhất $2 / 3$ tiêu chuẩn của tam chứng Whipple.

Insulin và các thuốc kích thích tiết insulin (chủ yếu là sulfonylureas) có thể làm gia tăng hạ đường huyết do cơ chế tác dụng của thuốc tác động trực tiếp ở người đái tháo đường so với các nhóm thuốc khác[4]. Nghiên cứu của chúng tôi cho thấy có tình trạng hạ đường huyết gia tăng ở người đái tháo đường có dùng sulfonylureas và dùng insulin lần lượt là 1,93 và 6,46 lần. Kết quả này tương tự với các nghiên cứu trước [2], [5].

Tiền sử nhập viện vì hạ đường huyết trong vòng 12 tháng trước đó là yếu tố tiên đoán hạ đường huyết với $\mathrm{OR}=5.46$. Kết quả này tương tự trong nghiên cứu của Kim và cộng sự cho thấy tiền sử hạ đường huyết làm tăng nguy cơ hạ đường huyết ở đái tháo đường típ 2 gần gấp 17 lần[8]. Do vậy, những người bệnh đái tháo đường đã từng bị hạ đường huyết nên được tư vấn, giáo dục về hạ đường huyết bao gồm nhận biết các triệu chứng, xử trí ban đầu và phòng ngừa hạ đường huyết; cách thử đường huyết tại nhà.

Điểm mạnh và hạn chế của nghiên cứu:

Đây là một trong các nghiên cứu đầu tiên tại Việt Nam xác định tỷ lệ hạ đường huyết tự ghi nhận ở người bệnh đái tháo đường típ 2 . Mặc dù việc sử dụng đo bằng máy thử đường huyết mao mạch tại nhà có thể chưa được phổ biến, nhưng việc tự ghi nhận các triệu chứng nghi ngờ hạ đường huyết bởi người bệnh có thể là cách thức tốt nhất cung cấp các thông tin hữu ích cho các bác sĩ lâm sàng. Bên cạnh đó, tính chính xác của tự ghi nhận triệu chứng có thể bị ảnh hưởng nhiều bởi sai lệch do nhớ lại (recall bias).

\section{KẾT LUÂN VÀ KIẾN NGHI}

Hạ đường huyết chiếm tỷ lệ khá cao trong số những người bệnh đái tháo đường típ 2 . Kết quả này cho thấy các bác sĩ cần hỏi các triệu chứng gợi ý hạ đường huyết, nhất là ở người bệnh đái tháo đường có các yếu tố như dùng sulfonylureas hoặc insulin hoặc có tiền sử nhập viện vì hạ đường huyết trong vòng 12 tháng trước đó tại mỗi lần tái khám. Bên cạnh đó, người bệnh đái tháo đường nên được hướng dẫn và tư vấn cách nhận biết và xử trí ban đầu biến chứng hạ đường huyết.

\section{TÀI LIỆU THAM KHẢO}

1. Bonds DE, Miller ME and Bergenstal RM (2010). "The association between symptomatic, severe hypoglycaemia and mortality in type 2 diabetes: retrospective epidemiological analysis of the ACCORD study." BMJ; pp 340:b4909.

2. Edridge CL, Dunkley AJ, Bodicoat DH, et al. (2015). "Prevalence and 
Incidence of Hypoglycaemia in 532,542 People with Type 2 Diabetes on Oral Therapies and Insulin: A Systematic Review and Meta-Analysis of Population Based Studies." PloS one. 10(6); pp e0126427.

3. Elizabeth M, Larry R, Michael JD, et al. (2011). "Assessment of severity and frequency of self-reported hypoglycemia on quality of life in patients with type 2 diabetes treated with oral antihyperglycemic agents: A survey study." BMC Research Notes. 4; pp 251258.

4. Evans Kreider K, Pereira K and P. B.I (2017). "Practical Approaches to Diagnosing, Treating and Preventing Hypoglycemia in Diabetes. Diabetes therapy : research, treatment and education of diabetes and related disorders." Diabetes Ther 8(6); pp 1427 1435.

5. Gonzalez C, Monti C, Pinzon A, et al. (2018). "Endocrinol Diabetes Nutr." Prevalence of hypoglycemia among a sample of sulfonylurea-treated patients with Type 2 diabetes mellitus in Argentina: The real-life effectiveness and care patterns of diabetes management (RECAP-DM) study. 65(10); pp 592-602.

6. Hsu PF, Sung SH and Cheng HM (2013). "Association of clinical symptomatic hypoglycemia with cardiovascular events and total mortality in type 2 diabetes: a nationwide population-based study." Diabetes Care. 36; pp 894-900.

7. Johnston SS, Conner $C$ and Aagren $M$ (2011). "Evidence linking hypoglycemic events to an increased risk of acute cardiovascular events in patients with type 2 diabetes." Diabetes Care. 34; pp 1164-70.

8. Park SY, Jang EJ, Shin JY, et al. (2018). "Prevalence and predictors of hypoglycemia in South Korea." Am J Manag Care. 24(6); pp 278-286.

9. Samya V, Shriraam V, Jasmine A, et al.
(2019). "Prevalence of Hypoglycemia Among Patients With Type 2 Diabetes Mellitus in a Rural Health Center in South India." Journal of primary care \& community health. 10; pp 1-7.

10. Shriraam V, Mahadevan S, Anitharani M, et al. (2017). "Reported hypoglycemia in Type 2 diabetes mellitus patients: Prevalence and practices-a hospital-based study." Indian journal of endocrinology and metabolism. 21(1); pp 148-153.

11. Stargardt $\mathbf{T}$, Gonder-Frederick $\mathbf{L}$ and A. C. Krobot KJ (2009). "Fear of hypoglycaemia: defining a minimum clinically important difference in patients with type 2 diabetes." Health and quality of life outcomes. 7; pp 1-8.

12. Tiruneh GG, Abebe $\mathbf{N}$ and D. G (2019). "Self-reported hypoglycemia in adult diabetic patients in East Gojjam, Northwest Ethiopia: institution based cross-sectional study." BMC Endocr Disord. 19; pp 17.

13. Vexiau P, Mavros P, Krishnarajah G, et al. (2008). "Hypoglycaemia in patients with type 2 diabetes treated with a combination of metformin and sulphonylurea therapy in France." Diabetes Obesity Metab. 10; pp 16-24.

14. Wild D, von Maltzahn R, Brohan E, et al. (2007). "A critical review of the literature on fear of hypoglycemia in diabetes: Implications for diabetes management and patient education." Patient Education and Counseling. 68(1); pp 10-5.

15. Williams SA, Pollack MF and D. M (2011). "Effects of hypoglycemia on health-related quality of life, treatment satisfaction and healthcare resource utilization in patients with type 2 diabetes mellitus." Diabetes Res Clin Pract. 91(3); pp 36370.

16. Zoungas S, Patel A and Chalmers J (2010). "Severe hypoglycemia and risks of vascular events and death." N Engl J Med. 363; pp 1410-8. 